\title{
Nöroanatomi Dersi İçin Bir Mobil Uygulama Önerisi
}

\author{
G. Tirkeş ${ }^{1}$, D. Gökpınar ${ }^{2}$, E. E. Arıcı ${ }^{3}$, A. Bayralı ${ }^{4}$
}

1*Atılım Üniversitesi, Mühendislik Fakültesi, Bilgisayar Mühendisliği Bölümü, Ankara, Türkiye, (ORCID: 0000-0003-0884-4876),guzin.tirkes@atilim.edu.tr

${ }^{2}$ Atılım Üniversitesi, Mühendislik Fakültesi, Bilgisayar Mühendisliği Bölümü (Mezun), Ankara, Türkiye (ORCID: 0000-0003-3769-9858),denizgokpinarr@gmail.com

${ }^{3}$ Atılım Üniversitesi, Mühendislik Fakültesi, Bilgisayar Mühendisliği Bölümü (Mezun), Ankara, Türkiye (ORCID: 0000-0002-5486-9575),ekinarici.ea@gmail.com

${ }^{4}$ Atılım Üniversitesi, Mühendislik Fakültesi, Bilgisayar Mühendisliği Bölümü (Mezun), Ankara, Türkiye (ORCID: 0000-0003-3961-8900), afbay1297@hotmail.com

(3rd International Congress on Human-Computer Interaction, Optimization and Robotic Applications June 11-13, 2021)

(DOI: $10.31590 /$ ejosat.950201)

ATIF/REFERENCE: Tirkeş, G., Gökpınar, D., Arıcı, E. E. \& Bayralı, A. (2021). Nöroanatomi Dersi İçin Bir Mobil Uygulama Önerisi. Avrupa Bilim ve Teknoloji Dergisi, (26), 197-202.

$\ddot{\mathbf{O} z}$

$\mathrm{Bu}$ çalışma, Tıp ve Sağlık Bilimleri Fakültesi öğrencilerinin nöroanatomi dersinde yer alan kas, kemik ve eklem konularını tekrar edebilmeleri için bir mobil uygulama geliştirmeyi amaçlamaktadır. Önerilen uygulama, öğrencilere öğretim elemanları tarafından hazırlanan çalışma soruları, videolar ve diğer kaynaklara erişim sağlamaktadır ve Android İşletim Sisteminde kullanılacak şekilde tasarlanmıştır. Öğrencilerin cevaplayacağı çalışma soruları neticesinde öğrencinin hangi konularda eksiği olduğunu tespit ederek bu eksiği gidermek için ilgili videolar sunarak öğrenmeyi pekiştirmek hedeflenmektedir. Çalışmada öğrencinin geri bildirimlerinden yararlanarak iyileştirilmeye gidilmesi her zaman ilk hedef haline gelmiştir. Bu amaçla, Atılım Üniversitesi Sağlık Bilimleri Fakültesi Fizyoterapi ve Rehabilitasyon Bölümü nöroanatomi dersi öğrencilerine bir anket uygulanmış, öğrencilerin mobil uygulama kullanım tercihleri, bir mobil uygulamayı eğitim amaçlı kullanımına yaklaşımları ölçülmüş ve sonuçları değerlendirilmiştir.

Anahtar Kelimeler: Mobil Nöroanatomi Uygulaması, Mobil Öğrenme Uygulaması, Aktif Öğrenme, Android uygulama.

\section{A Mobile Application Suggestion For A Neuroanatomy Course}

\begin{abstract}
This study aims to develop a mobile application for the Faculty of Medicine and Health Sciences students to practice the muscle, bone, and joint issues in the neuroanatomy course. The proposed application provides students with access to study questions, videos, and other resources prepared by instructors and is designed to be used on the Android Operating System. As a result of the students' study questions, it aims to reinforce the learning by determining which subjects the student lacks and by presenting relevant videos to overcome this deficiency. Making improvements by taking advantage of the student's feedback has always been the first goal in the study. For this purpose, a questionnaire was applied to the neuroanatomy course students of At1lim University Faculty of Health Sciences, Department of Physiotherapy and Rehabilitation, the frequency of using a mobile application, their approach to using a mobile application for educational purposes were asked and the results were analyzed.
\end{abstract}

Keywords: Mobile Neuroanatomy App, Mobile Learning App, Active Learning, Android App

\footnotetext{
* Sorumlu Yazar: guzin.tirkes@atilim.edu.tr
} 


\section{Giriş}

Nöroanatomi, Patoloji, Biyokimya gibi diğer tıp bilimlerinin temel bileşeni olan Anatomi eğitimi, Tıp Fakültesi eğitiminin en önemli derslerinden biri olarak görülmüştür (Demirtaş, Onay ve Günerigök, 2013:41). Son yıllarda, donanım ve yazılım sektörünün gelişimi ile teknoloji herkes tarafindan kullanılır hale gelmiştir. $\mathrm{Bu}$ durum eğitime de olumlu yönde yansımış ve bilgisayar destekli eğitimin kullanımı ve uygulamaları anlamlı bir biçimde artmıştır (Trifonova, 2003). KOVID 19 pandemisi ile de özellikle Medya Paylaşım Siteleri (Youtube, Dailymotion), Sosyal Medya (Twitter, Instagram), bloglar, podcast'lerden eğitim videolarının izlenme oranı artmış, kullanıcılar ihtiyaçları doğrultusunda e-öğrenme platformu dahi oluşturabilir duruma gelmiştir (Biswas, Roy K.ve Roy F., 2020).

$\mathrm{Bu}$ teknolojik gelişmelerin içinde kullanımı yaygınlaşan uygulamalardan biri de mobil uygulamalar olmuştur (Briz-Ponce, Juanes-Mendez, García-Peñalvo ve Pereira, 2016:136). Bu uygulamaların kullanım kolaylığı ve zamanı etkili kullanması açısından eğitimciler ve öğrenciler tarafından tercih edildiği gözlemlenmiştir (Trifonova, 2003). Mobil uygulamalar her alanda kullanıldığı gibi sağlık alanında eğitim gören öğrenciler tarafından da yaygın olarak kullanılmaktadır. Uygulamaların maliyetlerinin düşük olması ya da maliyetlerinin olmaması buna etken olmuştur (Steel, 2012:875). Bu bağlamda, istenilen bilgilere daha rahat erişebilmek açısından, anatomi eğitimi ile ilgili mobil uygulamaların daha sı kullanılabileceği öngörülebilir. Özellikle, taşınabilirlik konusu da ele alındığında, mini bilgisayarlar anatomi eğitiminde günden güne daha fazla kullanılmaktadır. Ancak, Fizik Tedavi ve Rehabilitasyon Öğrencilerinin, eğitimlerini desteklemek için kullandıkları mobil uygulamalarda birçok sorun yaşadığı gözlemlenmiştir. Örneğin, kullanılan uygulamanın seçilen bir dersin belli bir konusu ile ilgili ölçme-değerlendirme sürecini tam anlamıyla karşılayamadığ ve konu eksiğini giderme yönünde verilebilecek desteği yeteri kadar sağlayamadığı görülmüştür. Fizik Tedavi ve Rehabilitasyon Öğrencileri yüz-yüze aldıkları teorik bilgileri laboratuvar ortamında uygulasalar da müfredatlarında bulunan çoğu ders pekiştirme gerektirmektedir. $\mathrm{Bu}$ durum öğrencilere destek sağlayacak ve bilgilerini tazeleyecek bir uygulamanın sunulması gerektiği sonucunu doğurmuştur (Hisam, A.,Shafique, M. U., Khurshid, M. N., Hamza, A., Asad, M. B., ve Shakeel, T., 2019:432). Bu sayede öğrenciler okulda edindikleri bilgileri destekleme imkanı bulacaklardır. Örneğin, Google Play kullanılarak indirilebilecek Tıp ve Sağlık Bilimi Fakültesi öğrencileri için geliştirilmiş uygulamalar mevcuttur. Literatürde de benzer çalışmalara rastlanmıştır.

2017 yılında yapılan bir çalışmada Zhao ve Pardo, Tıp Fakültesi öğrencilerinin sınav başarısına etkisini araştırmak amacıyla myUniMate isimli bir uygulama geliştirmişlerdir. Uygulamanın öğrencilerin taşınabilir cihazlarına aktarılıp kullanımı sağlandığında öğrencilerin öğrenme hızlarının arttı̆̆ sonucuna varılmıştır (Yu ve Pardo, 2017:1). Bir başka çalışmada ise, öğrencilerin tıp alanı ile ilgili mobil uygulamaları kullanma sıklıkları araştırılmış ve öğrencilerin teknolojiye olan ilgilerinin arttığı sonucuna varılmıştır. Aynı zamanda mobil uygulamayı kullanarak klinik çalışma bilgilerini de arttırdıkları gözlemlenmiştir (Hisam, A.,Shafique, M. U., Khurshid, M. N., Hamza, A., Asad, M. B., ve Shakeel, T., 2019:432). Valencia Üniversitesi eğitimcileri tarafından yapılan bir çalışmada, Fizyoterapi Fakültesi öğrencileri için Android ve İS işletim sistemleri ile uyumlu bir mobil uygulama geliştirilmiştir. $\mathrm{Bu}$ uygulama ile eğitimciler hazırladıkları ders kaynaklarını sanal ortamda paylaşarak dersi daha etkili aktarmayı aynı zamanda zaman ve maliyetten tasarruf sağlayan bir öğrenme arac1 oluşturmayı amaçlamışlardır. Öğrencilerden uygulamayı telefonlarına indirip denemeleri istenmiş, sonuç olarak daha iyi bilgi paylaşımının olduğu ve öğrencilerin bilgiye doğrudan erişmekten memnun oldukları gözlemlenmiştir (Martinez-Arnau, Zarzoso, Espi, Alakhdar, Zurriaga ve Benitez-Martinez, 2014). Son yıllarda anatomi öğrenmesinin kolaylaştırılması için kullanılabilecek olan Artırılmış Gerçeklik (AG) teknolojisiyle ilgili yapılan bir başka çalışmada, AG fikrinin mobil uygulamalarla birleştirilmesi sonucunda öğrencilerin anatomi dersi konularına olan hakimiyetlerinin artacağı sonucuna varılmıştır. $\mathrm{Bu}$ çalışmada, öğrencilere tablet bilgisayar, akıllı telefon gibi belli çoklu ortam materyalleri sunulmuş ve uygulamaların kullanım özellikleri anlatılmıştır. Alınan sonuçlarda en dikkat çekici olan, öğrencilerin AG uygulamalarını bireysel öğrenme aracı olarak da kullanmak istemeleri olmuştur (Kurniawan, Suharjito, Diana ve Witjaksono,2018:80). Bir diğer çalışmada ise, öğrencilere insan iskeletini tanıtabilmek için bir mobil uygulama tasarlanmış ve 3B kontrol cihazı (Leap Motion Controller) kullanılmıştır. Akıllı telefon kullanan öğrencilerin uygulamayı kullanmaları sağlanmış ve $3 \mathrm{~B}$ iskeletin tüm detaylarını inceleyerek bir sınava tabi tutulmuşlardır. Uygulanan bu sınavda öğrenci başarısında büyük bir artış olduğu sonucuna varılmıştır (Nainggolan, Siregar ve Rahmi, 2016:465).

Yapılan çalışmaların ortak sonuçlarında, mobil uygulamalar desteği ile öğrencilerin ezbere dayalı, yoğun içerikli ders konularını kolay bir şekilde takip edebildikleri, aynı zamanda dersin öğretim elemanının da öğrencilerin başarısını takip edebildiği görülmüştür. $\mathrm{Bu}$ çalışmada, nöroanatomi konusunun bir mobil uygulama ile pekiştirilmesine aynı zamanda dersin öğretim elemanın da öğrencinin eksik konularını analiz etmesine olanak sağlanması amaçlanmıştır.

\section{Materyal ve Metot}

Bu çalışmada "Physiotherapy Mobile Learning Application", "Students Mobile Learning Application" ve "Medicine Mobile Learning Application" anahtar kelimeleri kullanılarak 2004-2020 y1lları arasındaki eğitim ile ilgili mobil uygulama makaleleri incelenmiştir. Aktif öğrenmeye destek sağlamak amacı ile bir mobil uygulama geliştirilmiştir. Önerilen uygulamada Agile Yazılım Geliştirme Yöntemi kullanılmıştır (Ilieva, Ivanov \& Stefanova, 2004). Uygulamanın geliştirme aşamalarına kullanıcılar da dahil edilmiştir. Çalışmada, kullanıcıların mobil uygulamalara bakış açılarını öğrenmek amacıyla bir ön test uygulanmış ve analiz edilmiştir. Anket, Atılım Üniversitesi Sağlık Bilimleri Fakültesi'nde 2020-2021 Bahar döneminde 48 Fizyoterapi ve Rehabilitasyon öğrencisine uygulanmış olup toplam 12 sorudan oluşmaktadır ${ }^{2}$. Çalışmanın bir sonraki aşaması

${ }^{2}$ https://docs.google.com/forms/d/154jihxFD7E4ADVDK5tOXN1LPWTDJuM3ELKE1jHalasA/edit 
öğrencilere uygulamanın kullanımı hakkında bilgi vermek ve öğrencinin uygulamayı kullanmasını sağlamak, sonrasında memnuniyet anketi (son test) ile sonuçları değerlendirmek olarak planlanmıştır. Ancak COVID 19 pandemisi nedeni ile dersler dönem arasında çevrimiçi devam ettiğinden çalışmanın devamı yüz-yüze eğitim başladığında tamamlanacaktır.

\subsection{Veri Toplama}

Çalışmamızın nitel bölümündeki anket, öğrencilerin nöroanatomi konusundaki bilgi seviyeleri ve nöroanatomi çalışma süreçlerindeki yöntemleri keşfetmek için uygulanmıştır. Bu amaç doğrultusunda Google Formlar çevrimiçi anket arac1 kullanılmıştır. Anket sorularının geçerliliği hakkında gerekli uzmanlardan yardım alınmıştır. Gelen geri bildirimler ile birlikte anket son haline getirilmiştir. Ankete Cronbach Alpha testi uygulanmış ve geçerliliği .72 olarak saptanmış olup geçerli sayılmıştır. İstatistiksel analiz için .05 anlamlılık düzeyi kullanılmıştır. Anketin ilk üç sorusu demografik bilgilerin belirlenmesi için tasarlanmıştır. Anketin diğer sorularında uygulamanın kullanımı ve faydası hakkında sorular içermektedir. Derecelendirme yöntemi olarak "Kesinlikle katılıyorum", "Katılıyorum", "Fikrim Yok", "Katılmıyorum", "Kesinlikle Katılmıyorum" ifadelerinin yer aldığı 5'li Likert ölçeği kullanılmıştır (Turan, Şimşek ve Aslan, 2015:186).

Çalışmaya Atılım Üniversitesi Sağlık Bilimleri Fakültesi Fizyoterapi ve Rehabilitasyon bölümünde öğrenim gören 48 (\%58,3 kız, \%41,7 erkek) lisans öğrencisi katılım göstermiştir. Anketin ilk adımı olan öntest, öğrencilerin uygulamayı kullanmadan önce sahip oldukları "nöroanatomi" dersi ile ilgili bilgi seviyelerini ve çalışma yöntemlerini incelemiştir.

\subsection{1. Çalışma Süreci}

Çalışmada, öğrencilerin nöroanatomi konusu için pratik sağlayabilecekleri bir ortam tasarlanmıştır (ADEE-1997). Uygulama, öğrencinin tekrar edeceği konu ile ilgili görsel içerik, anlık bilgi edinebilmeleri için flaş kartlar ve bilgi seviyelerini gözlemlemek için konuya özgü test sorularından oluşturulmuştur. Öğrenci, test sonucuna göre eksik olduğu konu ile ilgili bilgilendirici videolara erişebilmesi için "Youtube" platformuna yönlendirilmektedir. Uygulamada kullanılan konu içeriği Atılım Üniversitesi Tıp Fakültesi'nde aktif olarak eğitim vermekte olan nöroanatomi dersi öğretim üyesinden alınmıştır.

\subsection{2. Önerilen Uygulama}

ADEE-1997 mobil uygulaması, Sağlık Bilimleri Fakültesi Fizyoterapi ve Rehabilitasyon bölümünde eğitim gören öğrenciler için tasarlanmış olup müfredatlarının 2. döneminde aldıkları "Nöroanatomi" dersine katkı sağlamayı amaçlamıştır. Şekil 1' de önerilen uygulamanın mobil tarafında kullanılan programların diyagramı verilmiştir.

Mobil uygulamayı geliştirme sürecinde, ön yüz React Native platformunda yazılmış olup Visual Studio 2019 kullanılmıştır. Veritabanı olarak MsSQL Server, arayüz için IONIC yazılım çerçevesi kullanılmıştır. Uygulamanın ön yüzü

.NET Core'da yazılmış olup, arka yüzünde ise Angular 10 kullanılmıştır. Kullanıcı parola bilgileri md5 algoritması ile şifrelenmiştir (Qashlim ve Akhmad, 2016:10).

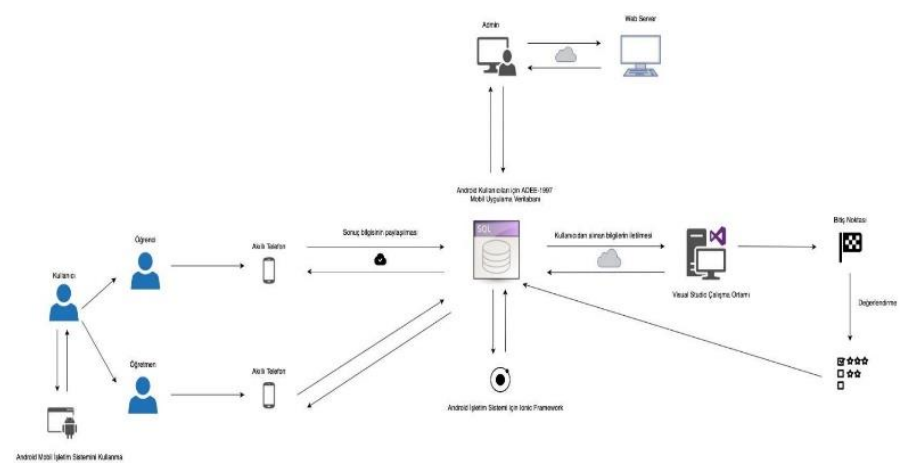

Şekil 1. Mobil Uygulamada Kullanılan Programlar

Uygulamada, öğretim elemanı ve öğrenciler için iki farklı arayüz tasarlanmıştır. Öğretim elemanı ve öğrenciler sisteme admin aracılığı ile kayıt olabilmektedir. Öğretim elemanı, kendi arayüzünü kullanarak öğrenciler için hazırladığı soruları ve flaş kartları sisteme girer. Soruları çözen öğrenciler puanlarını görebilir ve sınav sonuçlarına göre ders ile ilgili eksik noktaları belirleyip sistem tarafindan önerilen ders videolarını izler. Öğretim elemanı ise, öğrencinin puanını görebilir ve bu şekilde öğrencilerinin başarısını takip edebilir. Öğrenci ve öğretim elemanları "Yardım-Destek" bölümünden sistem ile ilgili sorunlarını veya görüşlerini e-posta üzerinden sistem adminine bildirebilirler. Şekil 2‘de sistem diyagramı verilmiştir.

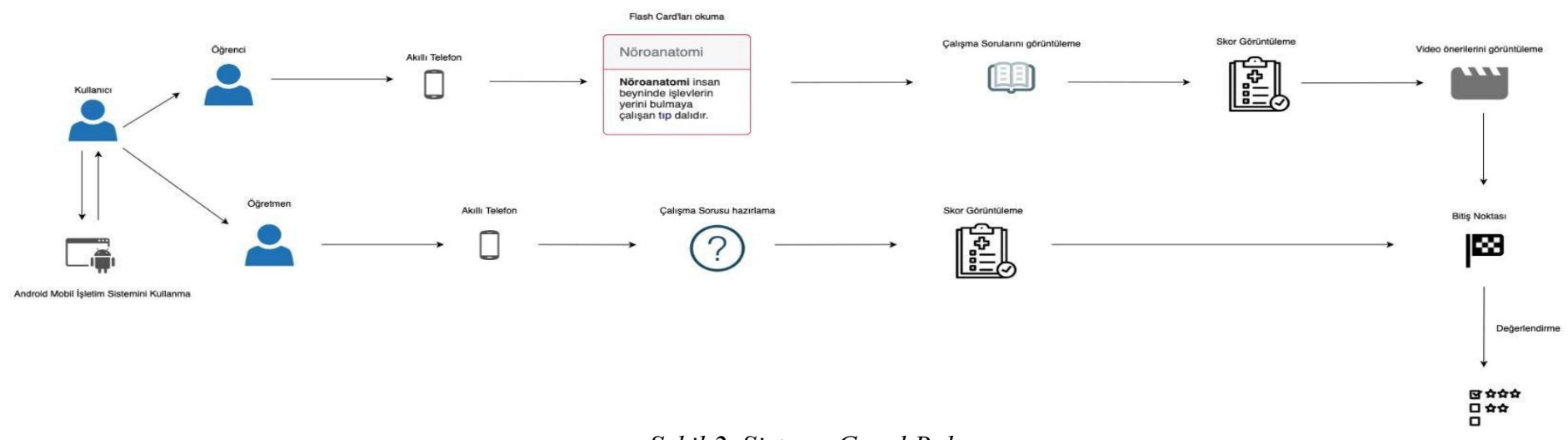

Şekil 2. Sisteme Genel Bakış 


\subsection{Yazılım Geliştirme Metodu}

ADEE - 1997 Mobil Uygulaması'nda yazılım geliştirme yaşam döngüsünde “Agile Method” kullanılmıştır. Bu metodun tercih edilme sebebi; yazılım geliştirme tekrarlı, dinamik ve değişime açık olmasıdır (Briz-Ponce, Juanes-Mendez, GarcíaPeñalvo ve Pereira, 2016:136).

$\mathrm{Bu}$ uygulama kullanıcı memnuniyetine odaklanmıştır. Bu nedenle kullanıcılar da geliştirme aşamasına dahil edilmiştir. Uygulama aşamalı olarak geliştirilmiş olup fonksiyonel, fonksiyonel olmayan ve sistem gereksinimleri belirlenmiştir. Benzer uygulamalara literatürden erişilmiş ve örnek alınmıştır. Uygulamanın ön yüz tasarımı React Native platformunda, yönetici panelinin ön yüzü ise Angular 10 ile yapılmıştır. Kullanıcı arka yüz tasarımı Visual Studio 2019, .NET Programlama Dili, yönetici arka yüzü de .NET Core ile yazılmıştır. Veri tabanı yönetim sistemi olarak MsSQL kullanılmıştır. Kullanıcı Parola Bilgileri md5 algoritması ile şifrelenmiştir. Analiz sonuçları da Excel PDF olarak dışa aktarılacak biçimde tasarlanmıştır.

\subsection{1. İşlevsel Gereksinimler}

Öğrenci uygulamaya öğretim elemanının sisteme kaydettiği okul numarası ve belirlenen şifresi ile girecek ve kaydedilecektir. Şekil 3 'te uygulamaya giriş ekranı verilmiştir.

Flaş kart, temel bilgileri öğrenmek için iyi kurulmuş bir eğitim yardımcısıdır (Murray, Phelps ve Altabbak, 2018:42). Öğrenci uygulamada yer alan flaş kart bilgilerine ve sınav sorularına erişilebilecek ve bu uygulanan sınavların sonuçlarını "Hesabım" bölümünden görüntüleyebilecektir. Şekil 5 ve Şekil 6'da uygulamada yer alan soru sayfası ve flaş kart bilgi sayfası verilmiştir. Öğrenci, sınav sorularından en az birini yanlış yaparsa sistem tarafindan başarısız sayılacak ve sistem öğrenciye kullanıcının çözdüğü sınav sorularının konusu ile ilgili video linki önerisinde bulunacaktır. Şekil 4'te öğrencinin sonuçlarını gördüğü sayfa görüntüsü verilmiştir.
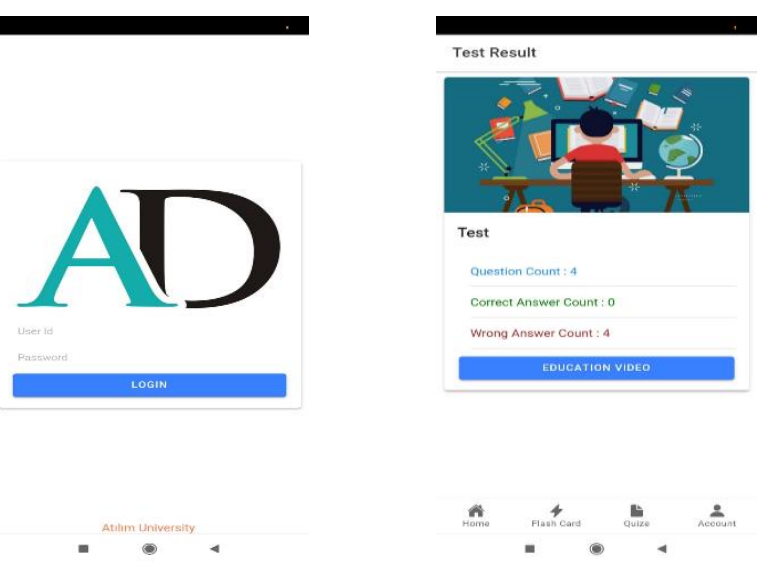

Şekil 3. Giriş Sayfası

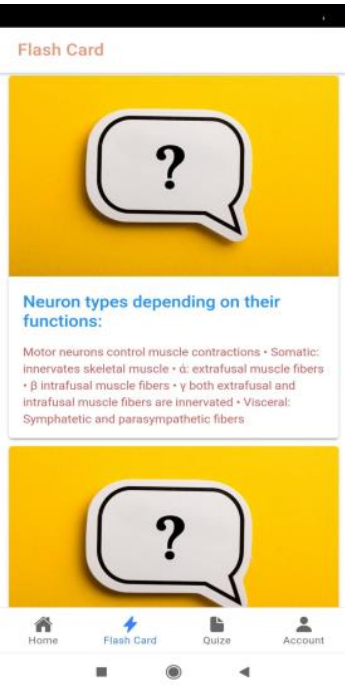

Şekil 5. Soru Sayfası

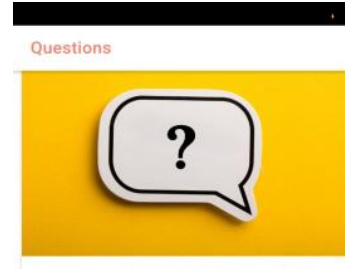
1. Nerves that carry impulses from
the periphery of the body to the brain:

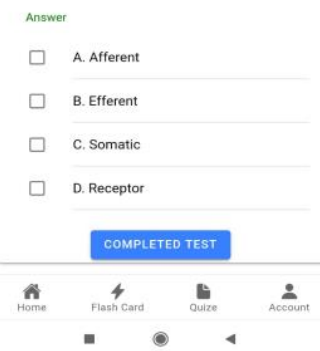

Şekil 6. Flash Kart Sayfast
Öğretim görevlisi, öğrencinin uygulamada yaptığı sınav not bilgilerini web kısmında yer alan "Puan Tablosu" butonundan görüntüleyebilecektir. Öğretim görevlisi sisteme yeni flaş kart bilgileri, yeni öğrenci, yeni konu ve yeni soru ekleyebilme ve çıkarabilme yetkisine sahiptir (Şekil 7 ve Şekil 8).

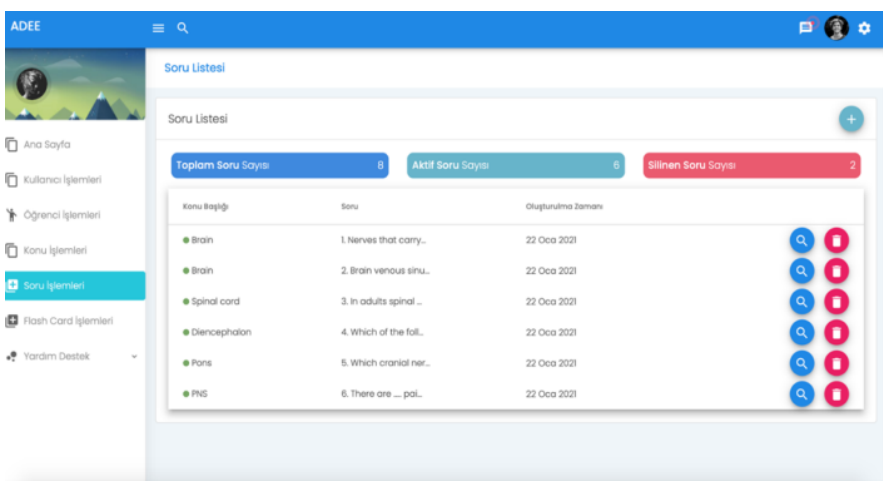

Şekil 7. Soru İşlemleri Sayfası

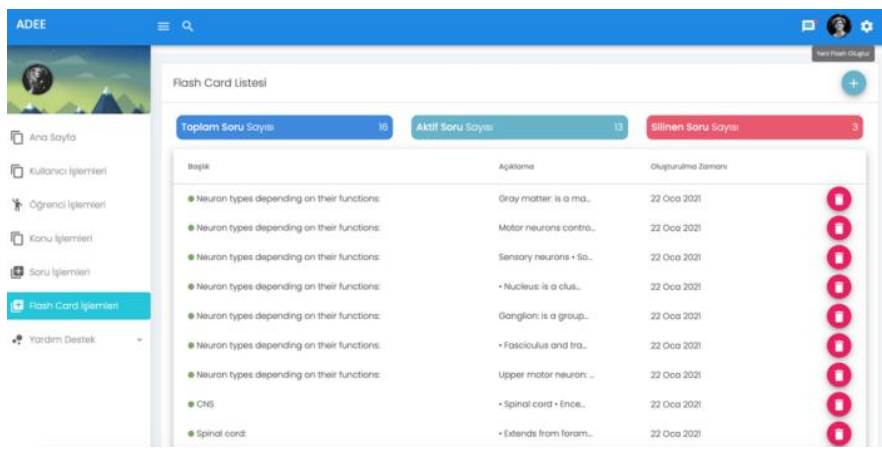

Şekil 8. Flaş Kart İşlemleri Sayfası

\subsection{1. İşlevsel Olmayan Gereksinimler}

Çalışmamızın mobil tarafi şu an için sadece Android cihazlar ile uyumludur. Uygulama açıldığında başlangıç ekranının yüklenmesi en fazla 5 saniye sürmektedir. Öğrencinin mobil tarafında yaptığı sınavların sonucu öğretim elemanının erişebildiği Web kısmına maksimum 30 saniye içinde görünür hale gelmektedir. Her öğretim elemanı sadece kendi öğrencisinin sonuçlarına erişilebilmektedir. Kullanıcı verileri arttığında, uygulama ve depolamanın gerçekleştirilme veya 
erişilebilme şeklini optimize eder ve bunları gecikmeden işler. Kullanıcı bilgileri (hem öğretim görevlisi hem de öğrenci için) şifrelenmiş dosyalarda ve içeriğine kolayca erişilemeyen özel bir dosya alanında saklanmaktadır. Mobil uygulamanın kullanımı öğretmenler ve öğrenciler tarafından kolaydır.

\section{Araştırma Sonuçları ve Tartışma}

$\mathrm{Bu}$ anket ile birlikte Atılım Üniversitesi Sağlık Bilimleri Fakültesi Fizik Tedavi ve Rehabilitasyon öğrencileriyle ADEE1997 mobil uygulaması için bir ön hazırlık yapılmıştır. Anketin amacı; öğrenci grubunun "Nöroanatomi" dersi hakkındaki bilgi düzeylerini öğrenmek ve mobil uygulamanın öğrencilerin dersi anlamalarına katkı sağlayıp sağlamayacağını anlamaktır.

Ankette S1 (Yaşınız?), S2 (Cinsiyetiniz?) ve S3 (Sınıfınız?) demografik soruları içermektedir. S7 - S12 arasındaki sorular, Likert ölçeği ile hazırlanmıştır. Ankete toplam 48 gönüllü öğrenci katılmıştır. Ankete katılan öğrencilerin yaşları \%10.4'ü 19, \%27.1'i 20, \%25'i 21 ve 22, $\% 4.2$ 'si 23 ve 34, \%2.1'i 24 ve 25 olarak değişmektedir. Öğrencilerin çoğunluğu 20, 21 ve 22 yaşlarında olup, \%41.7'si kadın, \%58.3'ü ise erkektir. Bu orana bakılarak fizik tedavi ve rehabilitasyon bölümünde okuyan erkek öğrencilerin oranının k1z öğrencilere göre daha fazla olduğu gözlemlenmiştir. Aynı zamanda, öğrencilerin \%87.5'i 2. sınıf, \%8.3'ü 1.sınıf, \%4.2'si 3.sinifta okumaktadir.

S4 (Fonksiyonel Nöroanatomi konusunda yeterli bilgiye sahip olduğunuzu düşünüyor musunuz?) sorusuna öğrencilerin \%72.9'u "Hayır" cevabını vermişlerdir. Bu nedenle ADEE1997 uygulaması bu grubu hedef almaktadır.

S5 (Haftada kaç saat Anatomi dersi alıyorsunuz?) sorusuna verilen yanıtlar şaşırtıcıdır. Öğrencilerin \%10.4'ü haftada 2 saat, \%47.9'u haftada 3 saat, \%20.8'i haftada 4 saat, \%6.3'ü haftada 6 saat, \%2.1'i haftada 7 saat anatomi dersi almaktadır. $\mathrm{Bu}$ sonuçlar kapsamında çalışmaya eşlik edecek öğrencilerin farklı sayılarda anatomi dersini almakta oldukları gözlemlenmiştir.

Öğrencilere anatomi çalışmaları için okul dışında haftada kaç saat harcadıkları sorulduğunda ise (S6) \%18.8'i 1 saat, \%35.4'ü 2 saat, \%18.8'i 3 saat, \%10.4'ü 4 saat, \%4.2'si 6 saat, $\% 2.1$ 'i 7 saat, \%4.2'si 8 saat, \%2.1'i 10 saat ve kalan \%4.2'si hiç vakit ayırmadıklarını söylemişlerdir. Bu sonuçlara göre yoğun olarak haftada 2 saat çalışan 17 öğrenci vardır ve sonuçlara bakıldığında 78 kişilik bir grupta çalışma saatleri net bir şekilde farklılık göstermektedir.

S7 (Anatomi dersine çalışırken veya sınavına hazırlanırken dersin kitaplarından yardım alırım.) sorusuna örneklemin \%22.9 "kesinlikle kat1liyorum", \%33.3 "katılıyorum" derken \%16.7 "fikrim yok", \%18.8 katılmiyorum ve \%8.3 ise "kesinlikle katılmıyorum" cevabını vermiştir. Anatomi eğitimi alırken öğrencilerin, internet ortamındaki kaynaklardan yardım alıp almadığı bir diğer önemli konudur.

S8'e (Anatomi dersine çalışırken sınavına hazırlanırken internetteki kaynaklardan yardım alırım.) öğrencilerin \%35.4'ü "kesinlikle katılıyorum" ve \%43.8 "katılıyorum" derken \%6.3 "fikrim yok", \%8.3 katılmıyorum ve \%6.3 ise "kesinlikle katılmıyorum" cevabını vermiştir. Verilen cevaplara göre öğrencilerin büyük bölümü internet kaynaklarını kullanmaktadır. S7 ve S8'i karşılaştıracak olursak, S7'ye verilen olumsuz cevapların (katılmıyorum ve kesinlikle katılmıyorum), anatomi dersine/sınavına hazırlanırken dersin kitaplarından yaralanmayan öğrencilerin çoğunun S8'e olumlu cevaplar (kesinlikle katıliyorum veya katıliyorum), yani anatomi dersine/sınavına hazırlanırken internetteki kaynaklardan yararlandıkları sonucuna varılmıştır.

S9'a (Anatomi dersine çalışırken veya sınavına hazırlanırken mobil uygulamalardan yardım alırım.) verilen cevapların ADEE-1997 uygulaması açısından büyük önem taşıdığı düşünülmektedir. Öğrencilerin \%20.8 "kesinlikle kat1liyorum" ve \%22.9 "kat1liyorum" derken \%14.6 "fikrim yok", \%20.8 "katılmiyorum" ve \%20.8 ise "kesinlikle katılmıyorum" cevabını vermiştir. Öğrenciler bu soruya verdikleri katılıyorum ve katılmıyorum cevapları eşit sayıdadır.

S10'a (Anatomi dersine çalışırken veya sınavına hazırlanırken Youtube üzerinden videolar izlerim.) öğrencilerin \%79.2'si olumlu cevap vermiştir. Bu yüzde katılımcı sayısının büyük bir çoğunluğunu temsil etmektedir ve ADEE-1997'de nöroanatomi ile ilgili "Youtube" linki önerileri verilmektedir. $\mathrm{Bu}$ nedenle uygulamanın katılımcıları memnun edeceği öngörülmektedir.

S11'e (Sınıf arkadaşlarım ile birlikte derse çalışırım/sınava hazırlanırım.) verilen cevaplar sonucu katılımcıların arkadaşları ile sınav/derse çalışma oranının (\%52.1) bireysel çalışma oranından fazla olduğu tespit edilmiştir. ADEE-1997 ile öğrencilerin bireysel çalışabilme oranlarının yükselmesi öngörülmektedir. Katılımcıların bilgi seviyesini ölçmek için hazırlanan anketin son sorusu

S12'ye, (Sinir sistemi anatomik organizasyonu konusuna hakimim) verilen cevapların \%54.2'sinin konuya hakim olmadığ $1, \% 10.4$ ' ünün fikri olmadığ 1 ve geri kalan kısmın ise konu hakkında yeterli bilgi seviyesine sahip oldukları sonucuna varılmıştır.

\section{Sonuç}

Bu çalışma, Nöroanatomi dersi alan öğrencilerin, konu eksikliklerini gidermeleri ve konuyu pekiştirmeleri için tasarlanan ADEE-1997 Mobil Uygulaması ile birlikte ilk incelemesinin gerçekleştirilmesi açısından dikkate değerdir. $\mathrm{Bu}$ tür uygulamalar incelenerek Nöroanatomi dersi müfredatlarında ve uygulamalarında kullanılmak üzere öğrencilere tavsiye edilmesi önerilir. Çalışmada mobil öğrenme yaklaşımıyla daha çok öğrencilerin bireysel öğrenimine odaklanılmıştır. Uygulama öğrencilere esnek ve bireysel bir ögrenme ortamı sunduğundan bu tür uygulamaların uzaktan eğitim ders kitaplarıyla bütünleştirilmesi de düşünülebilir. Çalışmanın planlanan son test aşamasında, ön test ile elde edilen sonuçlar ve öğrencilerin geribildirimleri göz önüne alınarak çalışmanın devamlılığının sağlanacağı düşünülmektedir. Araştırmanın geliştirilmiş olan bölümlerinde Yapay Zekâ, Sanal Gerçeklik, Artırılmış Gerçeklik gibi günümüzde öne çıkan birçok teknolojinin de çalışmaya entegrasyonunun sağlanması hedeflenmektedir.

\section{Teșekkür}

Çalışma için gerekli ders materyallerini sağlayan Atılım Üniversitesi Tıp Fakültesi Temel Tıp Bilimleri Dr. Öğr. Üyesi Hale Öktem'e, anket çalışmamıza destek veren Arş. Gör. Sena Nur Begen'e ve arayüz tasarımlarında destek sağlayan Ali Emre Yağcı'ya teşekkür ederiz. 


\section{Kaynakça}

Biswas, B., Roy, S. K. \& Roy, F. (2020). Students Perception of Mobile Learning during COVID-19 in Bangladesh: University Student Perspective. Aquademia, 4(2),ep20023. https://doi.org/10.29333/aquademia/8443

Briz-Ponce, L., Juanes-Méndez, J. A., García-Peñalvo, F. J., \& Pereira, A. (2016). Effects of Mobile Learning in Medical Education: A Counterfactual Evaluation. Journal of medical systems , 40(6), 136.

https://doi.org/10.1007/s10916-016-0487-4

Demirtaş, İ., Onay, T. ve Günerigök, F. (2019). Anatomi Eğitimi İçin Geliştirilmiş Mobil Uygulamalar. İstinye Üniversitesi, 41-49.

Hisam, A.,Shafique, M. U., Khurshid, M. N., Hamza, A., Asad, M. B., \& Shakeel, T. (2019). Usage and Types of Mobile Applications amongst Medical Students of Pakistan and its Association with their Academic Performance. University of Pakistan., 35 (2), 432-436.

doi: $10.12669 /$ pjms.35.2.672

Kurniawan, M. H., Suharjito, Diana \& Witjaksono, G. (2018). Human Anatomy Learning Systems Using Augmented Reality on Mobile Application. Procedia Computer Science Volume 135, 80-88.

https://doi.org/10.1016/j.procs.2018.08.152

Martinez-Arnau, F., Zarzoso, M., Espí, G., Alakhdar, Y., Zurriaga, L., Benitez-Martinez, J. \& Granell, J.C (2014). Mobile Resources for Access to the Audiovisual Information in Physiotherapy Studies at the University of Valencia. University of Valencia.

Murray, S., Phelps, J. \& Altabbakh, H. (2018). Enhancing Exam Prep with Customized Digital Flashcards. Journal of STEM Education, 19(4), 42-45.

Nainggolan, F.L., Siregar, B. \& Fahmi, F. (2016). Using Leap Motion Controller, Faculty of Computer Science and Information Technology, Department of Electrical Engineering, University of Sumatera Utara, Medan, Indonesia. 465-470.

doi: 10.1109/ICCOINS.2016.7783260

Rusdianto \& Qashlim, A. (2016). Implementasi Algoritma Md5 Untuk Keamanan Dokumen. Jurnal Ilmiah Ilmu Komputer Fakultas Ilmu Komputer Universitas Al Asyariah Mandar 2, 2, 10-15.

Steel, C. H. (2012). Fitting learning into life: Language Students' Perspectives on Benefits of Using Mobile Apps, $875-880$.

Trifonova, A. (2003). Mobile Learning - Review of the Literature. Informatica e Telecomunicazioni, University of Trento, DIT-03-009.

Turan, İ , Şimşek, Ü. ve Aslan, H. (2015). Eğitim Araştırmalarında Likert Ölçeği ve Likert-Tipi Soruların Kullanımı ve Analizi. Sakarya Üniversitesi Eğitim Fakültesi Dergisi , 0 (30) , 186-203. Erişim adresi https://dergipark.org.tr/tr/pub/sakaefd/issue/11235/134252

Yu, Z. \& Abelardo, P. (2017). Evolving the Design of a Mobile Application to Support Transition to Tertiary Education. University of Sydney.Volume 4(25), 1-14.

https://doi.org/10.3389/fict.2017.00025 